\title{
The Effects of Corporate Social Responsibility on Overseas Mergers and Acquisitions
}

\author{
Edward Fosu ${ }^{1 *}$ Deborah Asiedu ${ }^{1,2}$ \\ 1.School of Business Administration, Zhejiang Gongshang University, China \\ 2.School of Management, University of Electronic Science and Technology of China
}

\begin{abstract}
This survey studies the effects of corporate social responsibility (CSR) on overseas mergers and acquisitions (overseas M\&As) on acquirers' corporate social responsibility (CSR) using a sample of Ghana multinational firms and MBA students. This study reveals that firms with overseas M\&A activities experience an improvement in CSR performance during the post-acquisition period, and this positive effect is more distinctive when the acquisition of targets is from developed markets than from emerging or low-quality markets. Besides, acquirers significantly improve CSR performance following their overseas acquisitions, suggesting that acquirers initiate efforts to improve CSR performance to gain legitimacy in host countries. The study equally finds that host country legal origins, social norms, and the acquirers' exposure to multiple jurisdictions hold the keys to improving the CSR performance of acquirers. The results appear robust and valid to various measures of CSR and are effective when endogeneity concerns are addressed. Further analyses disclose that overseas M\&A firms with high CSR performance show greater CSR initiatives. Overall, our findings add to the field of literature on the influence of legal and social norm origins on shaping stakeholder-oriented practices by showing how overseas M\&As may aid as a critical channel through which overseas acquirers bond themselves to the better CSR practices of the host countries.
\end{abstract}

Keywords: Corporate Social Responsibility, Mergers and Acquisitions and Overseas Investment

DOI: $10.7176 / \mathrm{EJBM} / 13-6-15$

Publication date:March $31^{\text {st }} 2021$

\subsection{Introduction}

Corporate social responsibility (CSR) and mergers and acquisitions (M\&As) have increased in a substantial amount of exposure over the last three decades however, the amalgamation of the factors often goes unobserved (Lagas, 2013). The influence that CSR has on merging or acquisition is a phenomenon recently generating awareness (Lagas, 2013). At the point where social responsibility starts to affect the financial performance of a firm, it could be a corresponding factor in M\&A activity as well (Lagas, 2013). While research and awareness increase both in M\&A and in the CSR field, it is evident to see what the impact of the combination could be (Lagas, 2013). CSR practices are considered as organizational routines aimed at creating social value by reducing negative externalities or creating positive ones (Sethi 1990). Godfrey et al. (2009) posited that CSR can generate goodwill, leading to positive and remarkable credits from stakeholders who temper their adverse judgment and punitive sanctions during a negative event. Koh et al. (2014) also stipulated that CSR can enhance firm worth by functioning as an insurance mechanism for firms with high litigation risks. Previous studies have extensively studied the value creation and destruction of firms' acquisition activities for investors (Andrade et al. 2001; Moeller et al. 2004; 2005; Shleifer and Vishny 2003). In contrast, there is limited research work on the implication of M\&A activities for other stakeholders, in particular the effect of M\&As on CSR. By examining whether overseas M\&As, of firms, can affect CSR initiation. The focus is on the overseas acquisitions of firms for several reasons. Due to strict currency restrictions in some countries, foreign direct investment acquisition activities in those countries are mostly influenced by the government policies and initiatives on CSR. It is recognized in the literature that government usually intervenes in the market to serve various social, political and environmental agendas at the cost of shareholder wealth (Chen et al. 2018). The government's policies and initiatives on foreign investment about CSR are no exceptions. In contrast to domestic M\&As, firms engaging in cross-border acquisitions face significant and unique changes to their institutional environments. CSR is defined as the ongoing dedication by organizations to act ethically as well as to contribute to economic development, at the same time enhancing the quality of life of their employees, their families and the local community and society entirely. From this definition, it is evident that CSR is all about how organizations relate to the external and internal environment, in the course of pursuing their business motives. Stakeholder compositions at the minimum, through overseas acquisitions, firms are exposed to host countries' regulations, legal systems and social norms (Ahern et al. 2015; Erel et al. 2012). To gain legitimacy, acquirers also must meet the expectations of stakeholders in host countries, including customers, suppliers, employees, governments and public interest groups, whose expectations are likely to be different from those stakeholders in the home country. These reasons suggest that acquirers may need to take additional CSR initiatives following cross-border acquisitions. Moreover, stakeholders in the host countries are often concerned about the legitimacy of acquirers on social and environmental grounds. These social and environmental concerns 
may prevent acquirers from successfully pursuing their foreign investments and effectively integrating their global operations. The issue of gaining legitimacy therefore significantly affects the success of the overseas acquisitions of firms. Recognizing such barriers, the government specifically issues policies and guidance aimed at emphasizing the CSR practices of acquirer firms in host countries as a strategy to strengthen reputation and build legitimacy. By following some governmental policies and guidance, firms are expected to improve their CSR performance through cross-border acquisitions. Apart from the government-driven focus on CSR in overseas acquisitions, anecdotal evidence suggests firms have incentives to enhance their reputation domestically by acquiring strategic assets abroad. This is largely due to consumers placing greater trust in foreign products relative to domestic products and due to the environmental pollution in some countries. Most state regulations laid-down in developed countries helps to increase the performance of corporate social responsibility (CSR) than in developing countries. However, national institutions' disparities in the countries such as regulatory policies, national cultures, and social perception affect the performance of CSR. Language, social-behavioral norms and religious beliefs are examples of factors influencing cultural differences between two countries (Ghemawat, 2001). A different language is a major contributor to cultural distance. Differences in language between the home- and host countries make it costly to communicate information (Campbell, Eden \& Miller, 2012). As the cultural distance of the home country of an overseas subsidiary increases, so will the familiarity of the respective firm to the social behavioral norms of their host country. Getting adapted to the established social customs will be more demanding. A different language will add to the degree of difficulty in adapting to the established social norms (Ghemawat, 2001). It will also be more challenging to gauge what the expectations of the stakeholder environment are for CSR activities when there are language barriers. Hence, as the perceived cultural dissimilarity of the respective enterprise increases, local stakeholders have less desirability for a foreign firm to be operational in their society. When the cultural distance existence amid a firm's home- and host country becomes larger, the degree of goodwill that CSR can make decreases. This means the value of CSR may change in the eyes of managers from various institutional backgrounds (Matten, D.; Moon, 2008) also heterogeneity may exist in terms of managerial attitude and recognition towards the firm's CSR. Institutional distance may have an adverse impact on the acquirer's ability to learn and integrate the host firm's CSR practices. Even if the acquirer appreciates the firm's commitments to CSR and regards CSR as a strategic asset, it takes more comprehensive cost and time for the firm's CSR to function in a specific institutional environment. Transfer of certain CSR practices into other countries is more difficult where formal institutions are diverse. By conforming to the rules and beliefs well established and accepted within a specific environment, firms are more likely to meet the expectations of stakeholders, and thus to win a better chance of survival and future growth. This work is designed to explore the institutional challenges, mergers and acquirer's CSR performance in CSR initiatives.

\subsection{Constructs and Hypothesis Development}

Multinational Companies (MNC) investments into foreign firms are considered as Overseas Investment, which involves the day-to-day operations in the other country. Firms constantly seek out to work within the confines and norms of respective societies. That is, they attempt to assure that their activities are understandable and perceived by outside parties to be "legitimate." When expanding abroad, acquiring firms must satisfy host country stakeholder expectations to gain legitimacy. However, stakeholders from the host country often lack information for rationally evaluating these firms, and may develop negative perceptions about these firms based on negative stereotypes about their weak home country institutions (Kostova and Zaheer 1999).

Emerging markets including developing countries are defined to have weak corporate governance practices, poor environmental and labor rights protections, and lower levels of institutional quality, such negative stakeholder perceptions indicate a range of legitimacy challenges faced by acquirers. To eliminate the negative perceptions and obtain legitimacy, acquirers must adopt policies and practices to appear in line with host country institutions (Rathert 2016). Corporate Social Responsibility activities contribute to such policies and practices for some reasons. Previous research advocates that CSR initiatives can eliminate the negative impressions on acquirers from emerging markets, strengthen their reputation, and build legitimacy (Marano et al. 2017). This is because CSR practices are considered organizational routines aimed at creating social value by reducing negative externalities or creating positive ones (Sethi 1990). Overseas acquisitions heighten the ambiguity and complexity of the operating environment of acquirers, can gain legitimacy among their stakeholders by adopting CSR practices to overcome barriers. For example, Symeou et al. (2018) show that firms in extractive industries often invest in CSR to treat the key social and environmental disruptions that their extractive operations can cause when expanding abroad. Besides, the literature finds that the risk of adverse political, regulatory, and social sanctions/penalties prompts firms to engage in CSR activities. As a reward, CSR practices create a moral image and legitimacy for firms to shield them from potential negative consequences from their operations. In particular, Rathert (2016) finds that exposure to different kinds of host country institutions affects the CSR practices of acquirers. Specifically, national-level institutions including both formal institutions, such as the rule of law, and informal institutions, such as conventions and social norms, can shape the extent of CSR practices by firms (Ghoul et al. 2017; Ioannou and 
Serafeim 2012; Marano and Kostova 2016). We argue that, through the host country's legal origins and social norms, overseas acquisitions can influence the CSR initiatives of acquirers. Research on legal institutions shows that the degree to which legal traditions prioritize investor and private property rights help explain cross-country variation in CSR practices (Liang and Renneboog 2017; Kim et al. 2017).

Common law systems provide strong protection to shareholders while civil law systems underline strong social preference for stakeholder claims (La Porta et al. 1998; 2008). Based on these key features of different legal regimes, Liang and Renneboog (2017) find that firms from civil law countries achieve better CSR performance than their common-law counterparts. They attribute this finding to the stakeholder-oriented rule mechanisms of the civil law countries, which are consistent with the social preferences for good corporate behavior reflected by CSR. In contrast, they find that firms from socialist countries (e.g., China) have the lowest levels of CSR and attach less attention to environmental and social issues than those from a common or civil legal origin.

Variations in the legal institutions of host countries enable acquirers to adopt their CSR approaches according to local stakeholder expectations. For example, Liang and Renneboog (2017) suggest that common law systems have a positive and significant influence on the corporate governance and community involvement domains of CSR, while French civil law systems are more concerned with social- and labor-related issues. If firms expand their business in common law countries, they are likely to be required to follow the good practices of corporate governance and community involvement employed by their counterparts in the common law country. Social norms are defined as "a predominant behavioral pattern within a group, supported by a shared understanding of acceptable actions and sustained through social interactions within that group" (Nyborg et al. 2016, p. 42). By adhering to social norms and meeting the social expectations of different stakeholder groups, acquirers can strengthen their legitimacy and enhance their reputation in host countries (Carroll and Shabana 2010). Acquirers, engagement in CSR can show their willingness to align practices with global stakeholder norms and expectations. It also assures stakeholders of the commitment to product quality and safety, environmental and social stewardship, codes of conduct and anti-corruption behavior (Marano et al. 2017).

Moreover, Marano and Kostova (2016) find that firms are likely to be influenced by social norms in countries with more stringent and reputable CSR traditions than in their home countries. Dyck et al. (2018) provide evidence that foreign institutional investors influence the environmental and social performance of firms only when these investors are from countries with strong social norms toward CSR engagement, taken together the pressure coming from social norms in host countries forces acquirers to initiate efforts to improve their CSR performance. Knowledge is the most important resource in firms to perform substantial differentiation and thereby maintain competitive advantages in the market (Gupta and Govindarajan 2000). Knowledge transfer in organizations is formally defined as "the process through which one unit (e.g., group, department, or division) is affected by the experience of another" (Argote and Ingram 2000), and it is manifested through changes in performance. Knowledge transfer can occur through overseas acquisitions, which introduce new channels of knowledge flow and promote organizational learning (Luo and Tung 2017; Zahra et al. 2000). Targets and other firms in host countries possess the knowledge along with several dimensions, such as general knowledge about the local legal system, accounting and auditing standards, customs and social norms (Libby and Luft 1993; Nelson and Tan 2005). This knowledge is valuable to acquirers who wish to compete globally.

CSR-related knowledge transfer can occur through overseas acquisitions (Symeou et al. 2018; Tashman et al. 2018). Drezner (2000) suggests that globalization encourages firms to transfer environmental technologies and management systems from countries with strict environmental standards to countries that lack access to environmental technologies and capacities. For example, Geely, a Chinese automaker, acquired Sweden's Volvo in 2010 to obtain world-class automotive technology, especially advanced environmental technology systems. With green car ambitions, Geely develops electric cars to meet the rising demand for new energy vehicles in China. The CSR related-knowledge can help acquirers better manage various stakeholder needs in host countries.

We expect it is easy to have CSR-related knowledge transfer internally for acquirers. Much of the CSRrelated knowledge is protected by legal mechanisms, such as patents and trade secrets. Since acquirers seek this knowledge, they will acquire it in their overseas deals.

Moreover, CSR-related knowledge can be more easily transferred internally due to the shared organizational culture and language (Andersson et al. 2001; Tallman and Chacar 2011). With internationalization, corporations worldwide gradually integrate CSR practices into their operations. In the past decades, the CSR performance of firms has developed rapidly, especially for firms with overseas investments (Gugler and Shi 2008). In light of the above reasons, we state our main hypothesis:

\section{H1: Overseas acquisitions increase CSR initiatives.}

This paper additional studies the relationship between overseas M\&As and CSR engagement. The motives for acquisitions in a developed and developing country are different. As another option, firms undertaking acquisitions in a developing country are with the primary purpose of securing raw material suppliers to power and boost the country's economic growth, instead of competing in international markets (Deng, 2009). Then again, firms from the emerging market as latecomers lack managerial experience and knowledge, which drives them to carry out 
acquisitions in developed markets in pursuit of strategic goals, such as expanding capabilities by learning new knowledge and realizing corporate strategic transformation (Ruiand Yip, 2008). Acquirers investing in developed economies probably view internationalization as a mechanism to equip themselves with competitive advantages (Ding et al., 2017). A longer-term strategic perspective characterizes these firms, and they develop their capability to shape overseas operations consistently. Thus, compared with firms acquiring emerging-market targets, firms targeting in developed markets may have stronger incentives to improve CSR-related initiatives after deal completion, as CSR strategies are consistent with achieving these long-run strategic goals.

Most studies recognize that firms from developed economies on average have better CSR performance due to widespread adoption of CSR initiatives, more comprehensive CSR exposure and socially responsible consciousness in these countries (Ioannou and Serafeim, 2012; Preuss et al., 2016; Liang and Renneboog, 2017). Sethi et al. (2017) further highlight that the role of CSR in addressing environmental, bribery, and corruption issues is more salient among developed markets than among emerging markets.

Overseas activities, therefore, should encourage managers of acquirers to boost CSR through improved governance by bonding themselves to host countries' regulation, legal system and cultural environments to eliminate the negative perceptions and obtain trustworthiness, and generate CSR-based takeover synergies (e.g., leading to positive investor reaction to acquirers, better reputation, enhanced competitive advantages). Similarly, CSR practices are affected by state regulations, institutional arrangements, economic development and societal preferences across countries. Firms are more likely to act in a socially responsible manner if they are subject to strong, well-enforced state regulations, or high quality of corporate governance (Campbell, 2007).

Based on the discussion above, we propose that the acquirer's CSR performance should be more distinctive when the targets are from institutional environments with better CSR-regime, which leads to the hypothesis below: H2: Acquirer's CSR performances are distinctive when firms are from developed countries.

Differences in national institutions such as regulatory policies, legal systems, national culture, and social cognition may affect the performance of CSR. In other words, the value of CSR may change in the eyes of managers from various institutional backgrounds (Matten, D.; Moon, 2008). Giving the fact that overseas M\&As involve top managers from at least two countries, heterogeneity may exist in terms of managerial attitude and recognition towards the firm's CSR. Therefore, this study investigates how institutional factors affect the relationship between a firm's CSR and acquisition. The institutional theory aims to answer a fundamental question as to what makes organizations so comparable. It proposes that the similarity of organizational structures and actions comes from the homogenization process in an institutional environment (DiMaggio, P.J.; Powell, W.W.1983).

Organizations are likely to meet set expectations of stakeholders' by conforming to beliefs, and rules accepted within a specific environment. When applying the institutional logic to the research on the linkage between a firms' CSR and the overseas acquisition, we expect that a country's specific institutional environment affects managerial perceptions of the value of CSR. For instance, empirical studies have shown that the effect of CSR on overseas performance varies across countries in developed countries, CSR has a significantly helpful effect on overseas performance, however, and this effect disappears in developing countries.

Similarly, in the overseas acquisition, both transaction parties are rooted in their unique institutional environments. Institutional distance may have an impact on how the acquirer perceives and evaluates the firm's CSR. Adaptation becomes the firm's challenge, primarily because it requires changing its previous methods. If an organization is willing to adapt, it can in turn make it easier. Though it is important to note that when implementing CSR, it can be seen as harmful to the business proposition because a slight change in a firm's social responsibility structure has the potential to disrupt its CSR's stability.

Institutional distance is also a factor of an overseas acquisition on a firm's CSR which refers to the gap between two countries in terms of formal institutions such as political, judicial, and economic systems (Dikova, D.; Sahib, P.R.; Van Witteloostuijn, A. 2009). Distance affects managerial decisions. When integrating CSR, scholars have found that institutional distances between developed and developing economies are likely to result in different CSR implications and outcomes. Hence, we propose that;

\section{H3: Institutional distance of the host firm negatively affects CSR initiatives.}

Institutional distance increases the rigor for the managing team of a foreign acquiring firm to comprehend the institutional and legal requirements of the host country where a firm is surrounded (Kostova, T.; Zaheer,1999). Any socially responsible firm must conform to formal institutions such as laws and government regulations.

A firm's CSR reputation is a result of the relationship between the focal firm and its embedded institutions. As institutional distance increases, the acquirer may unable to accurately and objectively evaluate the firm's CSR because the former's understanding is controlled by its institutional environment. Therefore, a good CSR practice implemented by the firm in the host country may serve no purpose in the eyes of the foreign acquirer.

Previous research revealed that the macro institutional environment of a country vehemently influences and impacts the effect of CSR practices (Barin Cruz, L.; Dwyer, R.; Avila Pedrozo, E. 2009). It is even more difficult to transfer certain CSR practices into other countries where formal institutions are heterogeneous. For example, after Unilever acquired Ben and Jerry's in 2000. Ben and Jerry's CSR performance declined and its socially- 
oriented corporate culture weakened to some extent. Part of the reason is related to the difference in their organizational structures, which must conform to their respective institutional requirements (Mirvis, P.H. Commentary 2008). Even though the relevant stakeholders and both parties regarded this acquisition as successful spent a huge amount of time and costs to learn from each other and integrate their CSR practices. Therefore, we hypothesized that:

\section{H4: Institutional distance negatively affects the acquirer's managerial evaluation of the firm's CSR.}

\subsection{Methods}

The study employed a mixed-method research design. Specifically, we employed an interview and descriptive design that aims at collecting data to describe the situation and relations. We used relevant work related to the hypothesis as secondary data to support the quantitative methods. One hundred and thirty MBA students from three universities in Ghana volunteered to participate in the research. Again, a total of twenty (20) Chief Executive Officers and Human Resource Managers were selected from multinational companies in Ghana to solicit qualitative data. The study employed both probability and non-probability sampling techniques. Under the nonprobability sampling technique, a purposive sampling technique was employed to select managers of the Multinational companies for interviews. The qualitative study used in-depth interviews to generate data for analysis. In this case, the researcher used structured questionnaires that contained both closed and open-ended questions. This allowed them to freely express how they perceive the situation. The quantitative study used the questionnaire as an instrument to generate data from the students for analysis. The data gathered in the survey were coded in a 5-Likert-scale point. The questionnaires collected were sorted into those from respondents they were coded with numeric values to group them for analysis. The questionnaires were again sorted and collated. Statistical tools consisting of SPSS and Microsoft Excel were used in analyzing the final data.

\subsection{Descriptive analysis}

Regarding the gender of the respondents, out of the 150 respondents 90 of them representing $60 \%$ were males whiles $60(40 \%)$ were females. The ages of the respondents were of the Mean $=34.15$, median $=35$ and standard deviation of 4.646. The descriptive statistic for the overall survey revealed an overall mean score of 2.73 and a standard deviation of 0.34989 . V9 had the highest mean value $2.90(S D=1.079)$, indicating that firms undertaking acquisition in developing countries are with the primary purpose of securing raw material suppliers.

Table 1 gives insight into the descriptive statistics of our raw data for our variables employed herein.

\begin{tabular}{|c|c|c|c|c|c|}
\hline Items & $\begin{array}{c}\text { Sum } \\
\text { Statistic }\end{array}$ & $\begin{array}{c}\text { Mean } \\
\text { Statistic }\end{array}$ & $\begin{array}{c}\text { Std. Deviation } \\
\text { Statistic }\end{array}$ & $\begin{array}{c}\text { Skewness } \\
\text { Statistic }\end{array}$ & $\begin{array}{l}\text { Kurtosis } \\
\text { Statistic }\end{array}$ \\
\hline V1. & 386 & 2.57 & .689 & .419 & 1.849 \\
\hline V2. & 387 & 2.58 & .892 & -.331 & -.093 \\
\hline V3. & 410 & 2.73 & .473 & -1.446 & .992 \\
\hline V4. & 366 & 2.44 & .561 & .124 & -.660 \\
\hline V5. & 380 & 2.53 & .841 & -.862 & -.087 \\
\hline V6. & 408 & 2.72 & .715 & -1.313 & 1.958 \\
\hline V7. & 427 & 2.85 & .564 & -1.612 & 5.617 \\
\hline V8. & 413 & 2.75 & .768 & -.897 & 2.110 \\
\hline V9. & 435 & 2.90 & 1.079 & -.383 & -.751 \\
\hline V10. & 414 & 2.76 & .766 & -1.106 & 1.963 \\
\hline V11. & 422 & 2.81 & .536 & -1.463 & 5.263 \\
\hline V12. & 390 & 2.60 & .769 & -1.331 & .336 \\
\hline V13. & 428 & 2.85 & .572 & -.438 & 5.713 \\
\hline V14. & 420 & 2.80 & .733 & -.913 & 2.763 \\
\hline V15. & 415 & 2.77 & .746 & -.872 & 2.408 \\
\hline V16. & 408 & 2.72 & .906 & -.678 & .475 \\
\hline V17. & 426 & 2.84 & .715 & -.090 & 2.852 \\
\hline V18. & 426 & 2.84 & .752 & -.112 & 2.162 \\
\hline Total & 408.98 & 2.7265 & .34989 & -1.434 & 4.863 \\
\hline
\end{tabular}

Source: Authors' computations. NB: For the definition of variables, please see Table 3.

A bivariate correlation was conducted to evaluate the relationship among the variables used in table 3 , the variables; Developed markets promote strong CSR initiatives (V12), Regulatory policies differences affect CSR (V13), Institutional environment affects managerial decision (V14) and institutional environment affects acquirers' CSR perception (V15). There were significant relationships between all the variables; V13 and V12 with $r(148)=$ 
$.263, p<.01, \mathrm{~V} 14$ and V12, $r(148)=.274, p<.01, \mathrm{~V} 14$ and V13, $r(148)=.330, p<.01, \mathrm{~V} 15$ and $\mathrm{V} 12, r(148)=$ $.269, p<.01$, V15 and V13, $r(148)=.375, p<.01, \mathrm{~V} 15$ and $\mathrm{V} 14, r(148)=.270, p<.01$. In contrast, it notably discloses a negative correlation between firms undertaking acquisition in developing countries with the purpose of raw material suppliers (V9), CSR initiatives can eliminate the negative impressions (V4), CSR can enhance a firm's value (V5).

Table 2 Correlations Matrix

\begin{tabular}{|c|c|c|c|c|c|c|c|c|c|c|c|c|c|c|c|c|c|c|}
\hline & V1. & V2. & V3. & V4. & V5. & V6. & V7. & V8. & V9. & V10. & V11. & V12. & V13. & V14. & V15. & V16. & V17. & V18. \\
\hline V1. & 1 & & & & & & & & & & & & & & & & & \\
\hline \multirow[t]{2}{*}{ V2. } & $.198^{*}$ & 1 & & & & & & & & & & & & & & & & \\
\hline & .015 & & & & & & & & & & & & & & & & & \\
\hline \multirow[t]{2}{*}{ V3. } & $.287^{* *}$ & $.290^{* *}$ & 1 & & & & & & & & & & & & & & & \\
\hline & .000 & .000 & & & & & & & & & & & & & & & & \\
\hline \multirow[t]{2}{*}{ V4. } & .142 & .130 & $.293^{* * *}$ & 1 & & & & & & & & & & & & & & \\
\hline & .084 & .112 & .000 & & & & & & & & & & & & & & & \\
\hline \multirow[t]{2}{*}{ V5. } & $.187^{*}$ & $.247^{* *}$ & .141 & $.196^{*}$ & 1 & & & & & & & & & & & & & \\
\hline & .022 & .002 & .086 & .016 & & & & & & & & & & & & & & \\
\hline \multirow[t]{2}{*}{ V6. } & .028 & $.256^{* *}$ & $.294^{* *}$ & $.242^{* *}$ & $.261^{* *}$ & 1 & & & & & & & & & & & & \\
\hline & .731 & .002 & .000 & .003 & .001 & & & & & & & & & & & & & \\
\hline \multirow[t]{2}{*}{ V7. } & $.166^{*}$ & $.184^{*}$ & $.313^{* *}$ & $.294^{* *}$ & $.352^{* *}$ & $.285^{* *}$ & 1 & & & & & & & & & & & \\
\hline & .043 & .025 & .000 & .000 & .000 & .000 & & & & & & & & & & & & \\
\hline \multirow[t]{2}{*}{ V8. } & .066 & $.161^{*}$ & $.169^{*}$ & .098 & $.351^{* *}$ & $.179^{*}$ & $.454^{* *}$ & 1 & & & & & & & & & & \\
\hline & .421 & .049 & .039 & .234 & .000 & .029 & .000 & & & & & & & & & & & \\
\hline \multirow[t]{2}{*}{ V9. } & $.186^{*}$ & .075 & $.171^{*}$ & .051 & .067 & .137 & .055 & .083 & 1 & & & & & & & & & \\
\hline & .023 & .364 & .036 & .536 & .418 & .094 & .506 & .310 & & & & & & & & & & \\
\hline \multirow[t]{2}{*}{ V10. } & -.043 & .117 & .082 & $.185^{*}$ & .158 & .060 & $.449^{* *}$ & $.264^{* *}$ & .019 & 1 & & & & & & & & \\
\hline & .603 & .155 & .321 & .024 & .053 & .464 & .000 & .001 & .813 & & & & & & & & & \\
\hline \multirow[t]{2}{*}{ V11. } & -.090 & $.172^{*}$ & $.226^{* *}$ & .096 & .073 & $.160^{*}$ & .113 & .116 & $.258^{* *}$ & .135 & 1 & & & & & & & \\
\hline & .274 & .035 & .005 & .241 & .371 & .050 & .170 & .159 & .001 & .098 & & & & & & & & \\
\hline \multirow[t]{2}{*}{ V12. } & .056 & $.174^{*}$ & .129 & .115 & .145 & $.222^{* *}$ & $.189^{*}$ & $.173^{*}$ & $.219^{* *}$ & .087 & $.290^{* *}$ & 1 & & & & & & \\
\hline & .498 & .033 & .115 & .161 & .076 & .006 & .021 & .034 & .007 & .292 & .000 & & & & & & & \\
\hline \multirow[t]{2}{*}{ V13. } & -.024 & $.207^{*}$ & $.301^{* * *}$ & $.181^{*}$ & .080 & $.194^{*}$ & $.335^{* *}$ & $.238^{* *}$ & $.204^{*}$ & $.333^{* *}$ & $.457^{* *}$ & $.263^{* *}$ & 1 & & & & & \\
\hline & .774 & .011 & .000 & .026 & .331 & .017 & .000 & .003 & .012 & .000 & .000 & .001 & & & & & & \\
\hline \multirow[t]{2}{*}{ V14. } & .043 & $.251^{* *}$ & $.252^{* * *}$ & $.248^{* *}$ & $.207^{*}$ & $.328^{* *}$ & $.373^{* *}$ & $.293^{* *}$ & .110 & $.273^{* *}$ & $.229^{* *}$ & $.274^{* *}$ & $.330^{* *}$ & 1 & & & & \\
\hline & .605 & .002 & .002 & .002 & .011 & .000 & .000 & .000 & .179 & .001 & .005 & .001 & .000 & & & & & \\
\hline \multirow[t]{2}{*}{ V15. } & $.197^{*}$ & $.235^{* *}$ & $.165^{*}$ & $.231^{* *}$ & .157 & $.166^{*}$ & $.254^{* *}$ & $.274^{* *}$ & .154 & $.277^{* *}$ & $.209^{*}$ & $.269^{* *}$ & $.375^{* *}$ & $.270^{* *}$ & 1 & & & \\
\hline & .016 & .004 & .044 & .004 & .055 & .042 & .002 & .001 & .059 & .001 & .010 & .001 & .000 & .001 & & & & \\
\hline \multirow[t]{2}{*}{ V16. } & .119 & .144 & -.034 & $.165^{*}$ & $.277^{* *}$ & .127 & $.172^{*}$ & $.228^{* *}$ & .047 & $.261^{* *}$ & .044 & -.027 & .102 & $.289^{* *}$ & .072 & 1 & & \\
\hline & .146 & .078 & .675 & .044 & .001 & .122 & .036 & .005 & .570 & .001 & .595 & .743 & .216 & .000 & .384 & & & \\
\hline \multirow[t]{2}{*}{ V17. } & $.215^{* *}$ & .104 & $.210^{* *}$ & $.294^{* *}$ & .143 & $.187^{*}$ & $.246^{* *}$ & $.282^{* *}$ & $.171^{*}$ & .150 & .062 & $.188^{*}$ & $.238^{* *}$ & $.400^{* *}$ & $.282^{* *}$ & $.221^{* *}$ & 1 & \\
\hline & .008 & .204 & .010 & .000 & .081 & .022 & .003 & .000 & .037 & .067 & .453 & .021 & .003 & .000 & .000 & .007 & & \\
\hline \multirow[t]{2}{*}{ V18. } & .023 & $.209^{*}$ & $.181^{*}$ & $.279^{* *}$ & .104 & $.253^{* *}$ & $.170^{*}$ & .094 & .088 & $.189^{*}$ & .142 & .109 & $.179^{*}$ & $.283^{* *}$ & $.160^{*}$ & $.338^{* *}$ & $.502^{*}$ & 1 \\
\hline & .782 & .010 & .026 & .001 & .205 & .002 & .038 & .253 & .286 & .020 & .083 & .183 & .028 & .000 & .050 & .000 & .000 & \\
\hline
\end{tabular}

NB: For the definition of variables, please see Table 3

**. Correlation is significant at the 0.01 level (2-tailed).

*. Correlation is significant at the 0.05 level (2-tailed). 
Table 3 Variables display in this study

\begin{tabular}{ll}
\hline Items & Main variables/questionnaire \\
\hline V1 & M\&A's promote firms to seek legitimacy in the host country through CSR. \\
V2 & Weak home country institutions give negative perceptions about M\&A's firms. \\
V3 & Acquirers adopt policies and practices to obtain legitimacy with host country institutions. \\
V4 & CSR initiatives can eliminate the negative impressions on acquirers from emerging markets. \\
V5 & CSR can enhance a firm's value by functioning as an insurance mechanism for firms. \\
V6 & Variations in the legal institutions of host countries enable M\&A's to adopt CSR approaches towards \\
V7 & CSR-related knowledge transfer could occur through M\&A. \\
V8 & CSR - related knowledge could help acquirers better manage various stakeholder needs in host \\
V9 & $\begin{array}{l}\text { Firms undertaking acquisition in developing countries are with the primary purpose of securing raw } \\
\text { material suppliers. }\end{array}$ \\
V10 & $\begin{array}{l}\text { Firms from emerging markets as latecomers lack managerial experience and knowledge, which drives } \\
\text { them to carry out acquisitions in developed markets in pursuit of strategic goals. }\end{array}$ \\
V11 & $\begin{array}{l}\text { Acquirers investing in developed economies are more likely to view internationalization as a } \\
\text { mechanism to equip them with a competitive advantage. }\end{array}$ \\
V12 & $\begin{array}{l}\text { M\&A firms targeting the developed market may have stronger incentives to improve CSR - related } \\
\text { initiatives following deal completion to achieving these long-run strategic goals. }\end{array}$ \\
V13 & Differences in national institutions' regulatory policies affect the performance of mergers and acquirers' \\
V14 & CSR. \\
A country's specific institutional environment affects managerial decisions perceptions of the value of \\
C15
\end{tabular}

\subsection{Regression Analysis}

The objective of this research is to investigate the effects CSR has on overseas' M\&A's, to achieve this goal, it is very important to find out whether CSR policies of a country (CCP) and CSR related knowledge transfer (CRK) affect the legitimacy of Firms in an overseas' market (LFO). Multiple regression analysis was run from the variables obtained from the data collected from the respondents selected for this research. The regression equation formulated for the prediction was;

$$
Y=C+\beta 1 C C P+\beta 2 C R K
$$

Where; $\boldsymbol{Y}$ represents the legitimacy of Firms in an overseas' market, $\boldsymbol{C}$ denotes constant, $\boldsymbol{C} \boldsymbol{C P}$ represents CSR policies of a country, $\boldsymbol{C R K}$ represents CSR-related knowledge transfer. Indications from the table, shown that the linear combination of CSR policies of a country (CCP) and CSR related knowledge transfer (CRK) was significantly related to the legitimacy of Firms in an overseas' market (LFO), F $(2,146)=26.305, p<.001$. The multiple correlation coefficient was 0.52 , indicating that approximately $26.5 \%$ of the variance legitimacy of Firms in an overseas' market (LFO) can be justified. Hence, we accept our hypothesis and the equation becomes;

$$
\boldsymbol{Y}=1.381+0.244 \times(\boldsymbol{C C P})+0.320(\boldsymbol{C R K})
$$

\begin{tabular}{|c|c|c|c|c|c|c|c|}
\hline & \multicolumn{2}{|c|}{ Unstandardized Coefficients } & \multirow{2}{*}{$\begin{array}{c}\begin{array}{c}\text { Standardized } \\
\text { Coefficients }\end{array} \\
\text { Beta }\end{array}$} & \multirow[b]{2}{*}{$\mathrm{t}$} & \multirow[b]{2}{*}{ Sig. } & \multicolumn{2}{|c|}{ Collinearity Statistics } \\
\hline & $\mathrm{B}$ & Std. Error & & & & Tolerance & VIF \\
\hline Constant & 1.381 & .218 & & 6.324 & .000 & & \\
\hline $\mathrm{CCP}$ & .244 & .071 & .244 & 3.418 & .001 & .986 & 1.014 \\
\hline CRK & .320 & .054 & .425 & 5.954 & .000 & .986 & 1.014 \\
\hline
\end{tabular}

Table 4 coefficients

a. Dependent Variable: LFO.

A stepwise regression analysis was conducted in the table to determine how the Evaluation of host CRS (EHC) practices and Integration of CSR practices (ICP) predicted the Positive effects of CSR practices of a firm (PCP). At step 1 of the analysis Integration of CSR practices entered into the regression equation and was significantly related to the Positive effects of CSR practices of a firm $F(1,148)=49.762, p<.001$. The multiple 
correlation coefficient was 0.50 , indicating approximately $25.2 \%$ of the variance of Positive effects of CSR practices of a firm could be accounted for by Integration of CSR practices. Evaluation of host CRS practices did not enter into the equation at step 2 of the analysis $(t=.761, p=.448)$. Therefore, the equation for forecasting the Positive effects of CSR practices of a firm was:

$$
\boldsymbol{Y}=1.485+(0.477 \times \boldsymbol{I C P})
$$

Where; $Y$ represents Positive effects of CSR practices of a firm, 1.485 is the constant, 0.477 is the "beta" and ICP represents Integration of CSR practices.

Table 5 coefficients

\begin{tabular}{|c|c|c|c|c|c|c|c|}
\hline & \multicolumn{2}{|c|}{ Unstandardized Coefficients } & \multirow{2}{*}{$\begin{array}{c}\begin{array}{c}\text { Standardized } \\
\text { Coefficients }\end{array} \\
\text { Beta }\end{array}$} & \multirow[b]{2}{*}{$\mathrm{t}$} & \multirow[b]{2}{*}{ Sig. } & \multicolumn{2}{|c|}{ Collinearity Statistics } \\
\hline & $\mathrm{B}$ & Std. Error & & & & Tolerance & VIF \\
\hline Constant & 1.485 & .199 & & 7.473 & .000 & & \\
\hline ICP & .477 & .068 & .502 & 7.054 & .000 & 1.000 & 1.000 \\
\hline
\end{tabular}

a. Dependent Variable: PCP

Multiple linear regression was employed to find the effects that managerial experience of host firms (MEH) and strategic CSR goals of acquirer's internationalization (SCG) have on acquirer's performance in developed markets (APD)

The equation formulate was;

$$
Z=K+\beta 1 X+\beta 2 Y
$$

Where; $Z$ represents acquirer's performance in developed markets (APD), $K$ denotes constant, $X$ represents strategic CSR goals of acquirer's internationalization (SCG) and Y represents the managerial experience of host firms (MEH). The results from the regression output for the effect on acquirers' CSR performance distinctiveness when host firms are from developed countries as hypothesized. The evidence from table 6 shown that the linear combination of (SCG) and (MEH) was positively related to (APD), F $(2,147)=8.430, p<.001$. The multiple correlation coefficient was 0.32 , signifying that approximately $10.3 \%$ of the variance (APD) can be justified. Hence, we accept our hypothesis and the equation becomes;

$$
Z=1.388+0.182(X)+0.249(Y)
$$

\begin{tabular}{|c|c|c|c|c|c|c|c|}
\hline & \multicolumn{2}{|c|}{ Unstandardized Coefficients } & \multirow{2}{*}{$\frac{\begin{array}{c}\text { Standardized } \\
\text { Coefficients }\end{array}}{\text { Beta }}$} & \multirow[b]{2}{*}{$\mathrm{t}$} & \multirow[b]{2}{*}{ Sig. } & \multicolumn{2}{|c|}{ Collinearity Statistics } \\
\hline & B & Std. Error & & & & Tolerance & VIF \\
\hline Constant & 1.388 & .289 & & 4.798 & .000 & & \\
\hline SCG & .182 & .076 & .193 & 2.385 & .018 & .934 & 1.070 \\
\hline $\mathrm{MEH}$ & .249 & .095 & .212 & 2.620 & .010 & .934 & 1.070 \\
\hline
\end{tabular}

Table 6 coefficients

a. Dependent Variable: APD.

A hierarchical regression correlation was conducted to evaluate the relationship among the variables used to test hypothesis 3. The variables; Developed markets promote CSR initiatives (DMC) as independent variable while Regulatory policies differences affect CSR (RPD), Institutional environment affects managerial decision (IMD) and institutional environment affects acquirers' CSR perception (IAP) were predictors. There were significant relationships and all the variables entered the steps; $\operatorname{RPD}(\beta=.228, \mathrm{t}=2.697, \mathrm{p}=.008)$ IMD $(\beta=.217, \mathrm{t}=2.697$, $\mathrm{p}=.010)$ IAP $(\beta=.289, \mathrm{t}=2.496, \mathrm{p}=.014)$. Therefore, we accept our hypothesis.

Table 7 model summary

\begin{tabular}{llrrrrrrr}
\hline & & \multicolumn{5}{c}{ Change Statistics } \\
Model & R & R Square & Adjusted R Square & R Square Change & F Change & df1 & df2 & Sig. F Change \\
\hline 1 & $.341^{\mathrm{a}}$ & .116 & .104 & .116 & 9.672 & 2 & 147 & .000 \\
2 & $.397^{\mathrm{b}}$ & .158 & .141 & .042 & 7.227 & 1 & 146 & .008 \\
\hline
\end{tabular}

Dependent Variable: DMC

a. Predictors: (Constant), RPD, IMD

b. Predictors: (Constant), RPD, IMD, IAP.

4.3 Theoretical Analysis of Hypothesis 1, 2, 3 \& 4

H1: Overseas acquisitions increase CSR initiatives.

The social responsibility of a corporate organization takes on a two-fold nature thus internal and external corporate 
social responsibilities. The external, over the years, have gained much prominence at the expense of the internal. Internal corporate responsibility practices according to Turker (2009) are directly connected with the physical environs and psychological working atmosphere of the employee. It is expressed in health concerns and well-being of workers, their occupational training and partaking in the business, the impartiality of opportunities and workfamily relationship (Vives, 2006). Therefore, to reach a successful deal, merging and acquiring corporate enterprise take into consideration and account the needs and aspirations of workers.

Organizations with differentiation in their incentives, motivation and policies towards employees affect their external CSR initiatives. Organizations see the existing CSR practices and formulate policies that will differentiate their practices to gain the advantage of their competitors. The research shown firms are expected to merge or acquire with greater CSR similarities. Thus, when firms acquire overseas' investment CSR practices are initiated especially when firms have similar policies and implementations. Workers easily become acquainted with organizational changes and adapt to new initiatives. Investing in external firms is viewed as an avenue to gain entrance to international local markets and possibly realize competitive advantages via production cost efficiencies (Deutsche Bank Research, 2006). That is to stipulate the CSR initiatives are associated with the legitimacy of firms. Firms often connect with key stakeholders regarding their vision, mission, and values by divulging CSR practices. Moreover, CSR policies are determined by stakeholders' penchants (Benabou and Tirole (2010)) and thus reveal shared beliefs and values within the firm, defining corporate culture (e.g., Hoi, Wu, and Zhang (2013), Gao, Lisic, and Zhang (2014).

H2: Acquirer's CSR performances are distinctive when firms are from developed countries.

CSR practices and principles have been embraced for roughly 70 years in advanced and well-governed markets such as Japan, the U.K, the U.S and Germany (Husted, 2015), reason been to the point that CSR performance of advanced-market organizations is normally higher than that of emerging-market companies. CSR has not been seen as part of the corporates plan of several firms in the developing world. Over the previous years, some African countries have seen substantial progress in the spheres of human rights and CSR in countries like Kenya and South Africa (Visser, 2005) (Mwaura, 2004). However, this not as promising as it is anticipated in Ghana and countries where most areas have natural resources and are being exploited by several companies.

Through overseas' M\&As, firms secure the entrance to foreign resources and raw materials to upkeep the rapid growth of their economic growth of their country and companies as well. Such M\&A's target sectors inconsistent with the government's strategies to pursue resources security agenda, therefore this research shows M\&A's deals differ from countries to countries. A critical analysis of both legislations in Ghana and some developed seems to propose that although the state's laws make provision for the imposition of a fine on companies that flout CSR regulations but implementations become a challenge for a developing economy like Ghana.

Carroll (1991) explains that although companies seek out to maximize shareholders' value, all businesses must ensure they operate within the rules and regulations of their host countries.

\section{H3: Institutional distance of host firm negatively affects CSR initiatives.}

Companies are subjected to target countries' stakeholder structure, social norms, and organizational environments. If the acquirer principles or criteria are less austere or stern than the host's, the acquirer possibly will have to conform to the host corporate governance laws and the regulatory rules (Martynova and Renneboog, 2008). In an existing survey by Graham and Rajgopal (2015), 48\% of managers pointed out that they would give up on a prospective deal if there was cultural incompatibility, further $28 \%$ of managers said that they would agree on the deal but would need a markdown between $10 \%$ and $30 \%$ of the acquisition price of the target.

Similarly, cultural suitability is frequently stated by leaders as one of their encouraging motives in pursuing M\&A deals. Certainly, numerous recent prominent merger catastrophes (e.g., AOL-Time Warner and DaimlerChrysler) are frequently ascribed to the absence of cultural fit (Finkelstein (2002) and Dealbook (2010)). These shortfalls may discourage the implementation of tactics in foreign entities and obstruct the path to befitting competitive international actors. However, earlier research disclosed that variances between corporations might be a basis of value creation in a merger (Bouwman, 2013). For example, a value-increasing culture could be enforced on the target company due to a merger (Wang and Xie, 2009), or if the features of the dissimilarity among acquirer and host form complementarities. Therefore, one firm's fortes are the other company's weaknesses.

A well-known environment could support firms' practices to lure and retain the most wonderful workers and positively manage stakeholder dealings, which is predictably worthy for the corporation and achieves wider societal goals.

H4: Institutional distance negatively affects the acquirer's managerial evaluation of the firm's CSR.

The Ghana Business Code (GHBC) has major modalities of which underline the substance of CSR and are executed after present laws in Ghana.

Fascinatingly, firms are not forced by law to join the GHBC. It is an uncoerced measure, which permits the tasks and operations of companies to be looked at along four extensive classifications, that's human rights, anticorruption, environment and labor standards. Certificates conferred to members of organizations of good practice when operations are discovered to be consistent with the GHBC prescriptions. Through its freewill characteristic, 
not lots of companies have signed up to it. Of the countless Small \& Medium Size Enterprises (SMEs) and largescale industries that are members of the Ghana National Chamber of Commerce \& Industry (GNCCI) and the AGI, not more than 60 had joined the GHBC as of 01-04-2011.

This is conceivably caused by the anxiety of scrutiny that comes with the certification procedure and reveals the level of acceptability and gratitude of the concept in Ghana. However, these affect the firms' performance and assessment of firms CSR practices, mergers or acquirers find it very hard to evaluate domestic firms CSR practices. Although overseas' M\&A's may be an effective way to achieve growth in the end, lots of the corporations have writhed to attain positive performance. Studies have suggested that $60-70 \%$ of M\&A deals fail to deliver shareholder value and generally, the outcomes of these outbound M\&A deals are mediocre at finest. Some other issues, together with political instability, feeble legal structure and human rights in the intended countries, increase doubts on the long-term achievement of these resource-related investments.

The flexibility of the CSR laws in Ghana made it difficult for overseas' firms to evaluate domestic companies and this may affect the acquirer's capability to learn and incorporate the host firm's CSR practices.

\subsection{Conclusions}

The connection between overseas' M\&As and acquirers' CSR performance is anticipated to be positive since CSR engagement can be employed as a tactical tool to address stakeholders' concerns has relatively low CSR performance and perception (Renneboog, 2017), and robust government intervention, which frequently put Ghanaian firms in a competitive disadvantage in the international market.

It was shown in the analysis that weak governmental policies to make corporates responsible are lagging, making it difficult for overseas' firms to initiative CSR practices that will detriment the people. Notwithstanding, that Mergers and Acquirers would not have accurate information on domestic firms' ratings and outcomes of their CSR performances thereby making loose competitive advantage to other foreign firms.

It is therefore recommended that government should be proactive in the enactment and implementation of laws to properly regulate firms since CSR practices are an insurance mechanism for firms' legitimacy in operating overseas. There was evidence that overseas' acquisitions can alleviate the negative perceptions and the notion possessed by stakeholders that, operating in developing economies are for raw materials or resources but would see merging and acquisition as an avenue to learn various CSR- related knowledge and managerial skills.

Institutional distance rest on the notion that amount of firms CSR compatibility between firms involved in merger or acquisition is a crucial determinant of following the integration process (Cartwright \& Cooper, 1996; David \& Singh, 1994). It focuses on the correlation between pre-merger and post-merger outcomes, thus national and organizational altogether. Firms with CSR similarities are easy to merge or acquire than the other way round, it is acclaimed that institutional distance affects how stakeholders perceive host firms' CSR. Therefore, firms should have stronger CSR practices and policies to improve initiatives thereby fostering good deals and achieving long-term strategies goals.

There was evidence that acquirers or mergers find it difficult in assessing and evaluating host CSR practices due to institutional distancing. The institutional environment affects the acquirer's capability to learn and assimilate the host firm's CSR practices plus institutional distancing can pose barriers in achieving integration.

However, the creation of coherent culture and adaption to each other's CSR-related practices will decrease the uncertainties like employees' resistance and constraints due to firms' takeover. Explicitly, acquirers must please the hopes of target-firm stakeholders to get legitimacy when growing and operating business overseas. However, stakeholders of host firms commonly lack information for lucidly assessing acquirers, and could develop negative discernments about their transparency, and trustworthiness (Kostova and Zaheer, 1999). Collectively, the results acquired in this work suggest that successful overseas' M\&As are driven by enriched CSR performance and practices which lead to tangible consequences on corporate strategies.

\section{Conflicts of interest}

The authors declare no conflict of interest.

\section{References}

[1] Ahern, K. R., D. Daminelli, and C. Fracassi, (2015), Lost in translation? The effect of cultural values on mergers around the world, Journal of Financial Economics 117, 165-189.

[2] Andrade, G., M. Mitchell, and E. Stafford, (2001), New evidence and perspectives on mergers, Journal of economic perspectives 15, 103-120.

[3] Andersson, Ulf \& Forsgren, Mats \& Holm, Ulf. (2001). Subsidiary Embeddedness and Competence Development in MNCs A MultiLevel Analysis. Organization Studies - Organ. Stud. 22. 1013-1034. 10.1177/0170840601226005.

[4] Anil K. Gupta And Vijay Govindarajan, (2000). Knowledge Flows Within Multinational Corporations. Strategic Management Journal. P. 473-496 
[5] Archie B. Carroll, Kareem M. Shabana (2010) The Business Case for Corporate Social Responsibility: A Review of Concepts, Research and Practice. 85-105

[6] Bénabou, R. and Tirole, J. (2010). Incentives and prosocial behavior. American Economic Review, 96 (5), $1652-78$.

[7] Bouwman, Christa H. S. (2013). The Role of Corporate Culture in Mergers \& Acquisitions. Mergers and Acquisitions: Practices, Performance and Perspectives, NOVA Science Publishers, May 2013, Available at SSRN: https://ssrn.com/abstract $=2307740$

[8] Campbell, J.T., Eden, L. \& Miller, S.R. (2012), "Multinationals and corporate social responsibility in host countries: Does distance matter?", Journal of International Business Studies, vol. 43, no. 1, pp. 84-106.

[9] Carroll, A.B. (2000). Ethical challenges for business in the new millennium: Corporate social responsibility and models of management morality, Business Ethics Quarterly, 10, pp. 33-42.

[10] Cartwright, S., \& Cooper, C. L. (1996). Managing mergers, acquisitions, and strategic alliances: Integrating people and cultures(2nd ed.). Oxford: Butterworth \& Heinemann.

[11] Chen, Y.-C., M. Hung, and Y. Wang, (2018), The effect of mandatory CSR disclosure on firm profitability and social externalities: Evidence from China, Journal of Accounting and Economics 65, 169-190.

[12] Davies, I. and Crane, A. (2010). Corporate social responsibility in small and medium-sized enterprises: investigating employee engagement in fair trade companies, Business Ethics: A European Review, 19, pp. 126-141.

[13] Deng X, Kahn BE. (2009) Is Your Product on the Right Side? The "Location Effect" on Perceived Product Heaviness and Package Evaluation. Journal of Marketing Research. 46(6):725-738. doi:10.1509/jmkr.46.6.725_JMR6B

[14] Dikova, D., Sahib, P.R. \& Van Witteloostuijn, A. (2010), "Cross-border acquisition abandonment and completion: The effect of institutional differences and organizational learning in the international business service industry, 1981-2001", Journal of International Business Studies, vol. 41, no. 2, pp. 223-245.

[15] Ding, Q., Redeker, N. S., Pisani, M. A., Yaggi, H. K., \& Knauert, M. P. (2017). Factors Influencing Patients' Sleep in the Intensive Care Unit: Perceptions of Patients and Clinical Staff. American journal of critical care: an official publication, American Association of Critical-Care Nurses, 26(4), $278-286$. https://doi.org/10.4037/ajcc2017333

[16] DiMaggio, P. J., \& Powell, W. W. (1983). The iron cage revisited: Institutional isomorphism and collective rationality in organizational fields. American Sociological Review, 48, 147-160. doi:10.2307/2095101

[17] Dyck, Alexander \& Lins, Karl \& Roth, Lukas \& Wagner, Hannes. (2015). Do Institutional Investors Drive Corporate Social Responsibility? International Evidence. SSRN Electronic Journal. 10.2139/ssrn.2708589.

[18] Ghemawat, P. (2001), "Distance still matters", Harvard business review, vol. 79, no. 8, pp. 137-147.

[19] Ghoul, S. E., O. Guedhami, and Y. Kim, (2017), Country-level institutions, firm value, and the role of corporate social responsibility initiatives, Journal of International Business Studies 48, 360-385.

[20] Godfrey, P. C., C. B. Merrill, and J. M. Hansen, (2009), The relationship between corporate social responsibility and shareholder value: An empirical test of the risk management hypothesis, Strategic Management Journal 30, 425-445.

[21] Graham, J., C. Harvey, and S. Rajgopal, (2005), The Economic Implications of Corporate financial reporting, Journal of Accounting and Economics40, 3-73.

[22] Gugler, P., Shi, J.Y.J. (2009). Corporate Social Responsibility for Developing Country Multinational Corporations: Lost War in Pertaining Global Competitiveness? J Bus Ethics 87, 3-24. https://doi.org/10.1007/s10551-008-9801-5

[23] Ioannou, I. and G. Serafeim (2017). The consequences of mandatory corporate sustainability reporting: evidence from four countries. Harvard Business School Working Paper No. 11-100.

[24] Kaplan, Rami \& Kinderman, Daniel. (2017). The business-led globalization of CSR: Channels of diffusion from the U.S

[25] Koh, P.-S., C. Qian, and H. Wang, (2014), Firm litigation risk and the insurance value of corporate social performance, Strategic Management Journal 35, 1464-1482.

[26] Kostova, T., and S. Zaheer, (1999), Organizational legitimacy under conditions of complexity: The case of the multinational enterprise, The Academy of Management Review 24, 64-81.

[27] Lagas, F. (2013). The effect of corporate social performance on shareholder wealth in Mergers and Acquisitions. Masters Thesis. Tilburg University, School of Economics and Management, The Netherlands.

[28] L. Argote, Paul Ingram (2000), Knowledge Transfer: A Basis for Competitive Advantage in Firms. Organizational Behavior and Human Decision Processes. Vol. 82, No. 1, May, pp. 150-169, 2000.

[29] La Porta, Rafael, Florencio Lopez-de-Silanes, and Andrei Shleifer. (2006). "What Works in Securities Laws?" Journal of Finance, 61(1): 1-32.

[30] Liang, H., and L. Renneboog, (2017), On the foundations of corporate social responsibility, The Journal of Finance 72, 853-910. 
[31] Marano, V., P. Tashman, and T. Kostova, (2017), Escaping the iron cage: Liabilities of origin and CSR reporting of emerging market multinational enterprises, Journal of International Business Studies 48, 386408.

[32] Marc K. Drezner M.D. (2000). Each Venture Is a New Beginning. American Society for Bone and Mineral Research. https://doi.org/10.1359/jbmr.2000.15.1.1

[33] Matten, D. \& Moon, J. (2008), "Implicit" and "explicit" CSR: a conceptual framework for a comparative understanding of corporate social responsibility", Academy of Management Review, vol. 33, no. 2, pp. 404424.

[34] Mitchell Lee Marks, Mirvis, P., \& Leo F. Brajkovich. (2001). Making Mergers and Acquisitions Work: Strategic and Psychological Preparation [and Executive Commentary]. The Academy of Management Executive (1993-2005), 15(2), 80-94. Retrieved February 10, 2021, from http://www.jstor.org/stable/4165737

[35] Rathert, N., (2016), Strategies of legitimation: MNEs and the adoption of CSR in response to host-country institutions, Journal of International Business Studies 47, 858-879.

[36] R. Libby, J. Luft, (1993), Determinants of judgment performance in accounting settings: Ability, knowledge, motivation and environment, Accounting, Organisations and Society, 18 (5) (1993), pp. 425-450

[37] Rui, Huaichuan and Yip, George S., (2008), Foreign acquisitions by Chinese firms: A strategic intent perspective, Journal of World Business, 43, issue 2, p. 213-226.

[38] Sethi, S. P., (1990), An analytical framework for making cross-cultural comparisons of business responses to social pressures, in L. E. Preston ed, Intimation and comparative corporation and society research. (JAI Press, Greenwich, CT).

[39] Symeou, P. C., S. Zyglidopoulos, and P. Williamson, (2018), Internationalization as a driver of the corporate social performance of extractive industry firms, Journal of World Business 53, 27-38.

[40] Turker, Duygu. (2009). Measuring Corporate Social Responsibility: A Scale Development Study. Journal of Business Ethics. 85. 411-427. 10.1007/s10551-008-9780-6.

[41] Visser, Wayne. (2005). Corporate Citizenship in South Africa. Journal of Corporate Citizenship. 2005. 10.9774/GLEAF.4700.2005.su.00007.

[42] Vives, A. (2006). Social and environmental responsibility in small and medium enterprises in Latin America, Journal of Corporate Citizenship, Spring, pp. 39-50.

[43] Wang, Cong and Xie, Fei, Corporate Governance Transfer and Synergistic Gains from Mergers and Acquisitions. Review of Financial Studies, Forthcoming, Available at SSRN: https://ssrn.com/abstract $=987113$

[44] Yi-Min Chen, Hsin-Hsien Liu, Yu-Ting Ni, Meng-Fen Wu, (2015). A rational normative model of international expansion: Strategic intent perspective, market positions, and founder CEOs/family-successor CEOs, Journal of Business Research, https://doi.org/10.1016/j.jbusres.2015.01.048. 